\title{
Health behaviours, socioeconomic status and diabetes incidence: the Australian Diabetes Obesity and Lifestyle Study (AusDiab)
}

\author{
E. D. Williams • R. J. Tapp • D. J. Magliano • \\ J. E. Shaw • P. Z. Zimmet • B. F. Oldenburg
}

Received: 10 June 2010 /Accepted: 5 August 2010 /Published online: 26 August 2010

(C) Springer-Verlag 2010

\begin{abstract}
Aims/hypothesis To identify the impact of socioeconomic status on incident impaired glucose metabolism and type 2 diabetes and to investigate the mediating role of health behaviours on this relationship using national, populationbased data.

Methods The Australian Diabetes Obesity and Lifestyle (AusDiab) Study is a national, population-based, longitudinal study of adults aged 25 years and above. A total sample of 4,405 people provided complete baseline (1999-2000) and 5 year follow-up (2004-2005) data relevant for these analyses. Fasting plasma glucose and $2 \mathrm{~h}$ plasma glucose were obtained from an OGTT, and demographic, socioeconomic and behavioural data were collected by interview and questionnaire. Multinomial logistic regression examined the role of socioeconomic position in the development of diabetes and mediation analyses tested the contribution of health behaviours in this relationship.

Results Highest level of education was a stronger predictor of incident impaired glucose tolerance and type 2 diabetes
\end{abstract}

E. D. Williams $(\bowtie) \cdot$ B. F. Oldenburg

School of Public Health and Preventive Medicine,

Monash University, Alfred Hospital,

89 Commercial Road,

Melbourne, Victoria 3004, Australia

e-mail: emily.d.williams@monash.edu

R. J. Tapp · D. J. Magliano - J. E. Shaw • P. Z. Zimmet

Baker IDI Heart and Diabetes Institute,

75, Commercial Road,

Melbourne, Victoria, Australia

R. J. Tapp

Department of Medicine,

Monash Medical Centre Southern Clinical School,

Monash University,

Melbourne, Victoria, Australia $(p=0.002)$, compared with household income $(p=0.103)$, and occupational grade $(p=0.202)$. Education remained a significant independent predictor of diabetes in fully adjusted models. However, the relationship was attenuated by the health behaviours (smoking and physical activity). Mediation analyses indicated that these behaviours were partial mediators (explaining 27\%) of the socioeconomic status-diabetes relationship.

Conclusion/interpretation Smoking and physical activity partly mediate the relationship between low education and type 2 diabetes. Identification of these modifiable behavioural mediators should facilitate the development of effective health promotion campaigns to target those at high risk of developing type 2 diabetes.

Keywords Prediction and prevention of type 2 diabetes . Exercise $\cdot$ Socioeconomic aspects $\cdot$ Mediation

$\begin{array}{ll}\text { Abbreviations } \\ \text { FPG } & \text { Fasting plasma glucose } \\ \text { IFG } & \text { Impaired fasting glucose } \\ \text { IGT } & \text { Impaired glucose tolerance } \\ \text { NGT } & \text { Normal glucose tolerance } \\ \text { SES } & \text { Socioeconomic status } \\ \text { 2hPG } & \text { 2-Hour plasma glucose }\end{array}$

Introduction

The prevalence of type 2 diabetes is rapidly increasing globally [1]. Environmental risk factors for type 2 diabetes are reasonably well established [2] but the impact of socioeconomic status (SES) is not well understood in relation to these. Although the strong relationship between SES and ill health [3] has been observed in prevalence 
studies of type 2 diabetes [4], few population-based studies have examined the socioeconomic predictors of impaired glucose metabolism prospectively [2, 5-7].

The development of type 2 diabetes is a multifactorial process that occurs over a lifetime [8]. The early risk factors for glucose metabolism impairment are catalysts for later risk factors, for example, socioeconomic factors influence an individual's life at an early age [3], contributing to the development of unhealthy behaviour patterns over the life course [9], which in turn promote obesity and inflammation [10]. Risk factors and associated health behaviours interact with one another and cascade over the life course but most studies tend to test for the significance of all risk factors in one model [4]. Some recent studies have begun to recognise the pathways through which socioeconomic adversity may promote disease progression [4, 11-13]. For example, prevalence and incidence data have indicated that physical activity and smoking may partly explain the relationship between socioeconomic adversity and diabetes [4, 11, 12]. These studies, however, have not employed adequate mediation analyses, nor have they included objective measures of diabetes status, and the results have been inconsistent [4, 11-13].

The aim of this paper is to investigate the mediating role of health behaviours in the relationship between SES and impaired glucose metabolism, using data across all categories of glucose metabolism from a national, population-based sample.

\section{Methods}

Study population The Australian Diabetes Obesity and Lifestyle Study (AusDiab) baseline methods and response rates are described in detail elsewhere [14]. In brief, it was a national, population-based survey of 11,247 adults aged $\geq 25$ years in 1999-2000. A stratified cluster sample was drawn from 42 randomly selected census collector districts across Australia. Information was collected using a brief household interview, followed by a biomedical examination. Of the eligible adults, $70 \%$ completed the household interview, and 55\% $(n=11,247)$ of these completed the baseline biomedical examination [15]. In 2004-2005, all living eligible participants were invited to attend follow-up. Those who were considered ineligible included those who refused further contact $(n=128)$, were deceased $(n=310)$, had moved overseas or into a nursing facility classified for high care, or had a terminal illness $(n=21)$. Among those eligible, 6537 returned for the 5 year follow-up where baseline assessment was repeated; the response rate was $60.6 \%$. Compared with those who did not attend, attendees were significantly less likely to be hypertensive, to have a lower level of education attainment, or to be smokers and to have lower $2 \mathrm{~h} \mathrm{PG}, \mathrm{HbA}_{1 \mathrm{c}}$, and smaller waist circum- ferences at baseline. Furthermore, a significantly larger proportion of non-attendees had abnormal lipid profiles at baseline compared with attendees [2]. Only those people with complete data were included in these analyses $(n=$ 4,405). The study was approved by the International Diabetes Institute Ethics Committee, and written informed consent was obtained from all participants.

Measurements At baseline and follow-up, the physical examination included blood samples, anthropometric measurements and questionnaires. All participants except for those currently receiving treatment for diabetes or who were pregnant underwent a standard $75 \mathrm{~g}$ OGTT [15]. Details on the glucose and lipid assays used between studies can be found in detail elsewhere [2]. High levels of triacylglycerols were classified as serum triacylglycerols $\geq 2.00 \mathrm{mmol} / 1$ [2]. Treated hypercholesterolaemia was defined as anyone taking lipid-lowering medication. Blood pressure was measured using Dinamap or a standard mercury sphygmomanometer with appropriate adjustments made as previously described [14]. Hypertension was defined as having systolic blood pressure $\geq 140 \mathrm{mmHg}$ or diastolic blood pressure $\geq 90 \mathrm{mmHg}$ or reporting use of medication for treatment of hypertension. Height, weight and waist were measured as described previously [15] and the BMI was calculated as weight $(\mathrm{kg})$ divided by height $\left(\mathrm{m}^{2}\right)$.

Diabetes classification was based on plasma glucose results, using the 1999 WHO diabetes classification, as used previously [2]. Type 2 diabetes was classified on the basis of fasting plasma glucose (FPG) $\geq 7.0 \mathrm{mmol} / 1$ or $2 \mathrm{~h}$ plasma glucose $(2 \mathrm{hPG}) \geq 11.1 \mathrm{mmol} / 1$ or current treatment with insulin or oral hypoglycaemic agents. For those not reporting treatment for diabetes, FPG $<7.0 \mathrm{mmol} / 1$ and $2 \mathrm{hPG} \geq 7.8 \mathrm{mmol} / 1$ but $<11.1 \mathrm{mmol} / 1$ indicated impaired glucose tolerance (IGT), FPG 6.1-6.9 mmol/1 and 2hPG $<7.8 \mathrm{mmol} / \mathrm{l}$ indicated impaired fasting glucose (IFG), and both $\mathrm{FPG}<6.1 \mathrm{mmol} / 1$ and $2 \mathrm{hPG}<7.8 \mathrm{mmol} / \mathrm{l}$ indicated normal glycaemia. An incident case of diabetes was defined as an individual who had normal glycaemia, IFG, or IGT at baseline but had developed diabetes by follow-up. Incident cases of IFG were defined as people who had normal glycaemia at baseline but had developed IFG at follow-up. Incident cases of IGT were defined as people who had normal glycaemia at baseline but had developed IGT at follow-up (this varied from the WHO classification of incident IGT, which incorporated baseline IFG). People with existing and newly diagnosed diabetes at baseline were excluded from the analyses.

Data on SES (education, total household income and occupational grade) were collected by an intervieweradministered questionnaire, as was information on smoking, leisure-time physical activity, and family history of diabetes. Education was classified into four categories, following 
responses to the question enquiring about the highest educational qualifications received: (1) secondary school education; (2) trade/technical certificates; (3) associate degree, undergraduate diplomas, nursing/teaching qualifications; and (4) bachelor degree, postgraduate qualifications. Total household income per week (in Australian dollars) was assessed by a question asking the participant to choose the closest income band for their total household income before tax. The responses were split into four groups: (1) people receiving $<\$ 400$; (2) those receiving $\$ 400-\$ 800$; (3) those receiving $\$ 800-\$ 1,500$, and (4) those receiving $>\$ 1,500$. Participants were asked what kind of job their 'main job' was, the job in which they 'usually worked the most hours'. Retired people were asked a similar question about their 'main job' before retirement. These responses were coded into three categories: (1) professionals; (2) white collar employees; and (3) blue collar employees. Smoking history (current smoker, past smoker, or never smoked) was collected using a questionnaire on tobacco use that has been validated in Australian adults [16]. Total leisure-time physical activity reported for the previous week (none; insufficient: 1-149 min; sufficient: $\geq 150 \mathrm{~min}$ ) was measured using the Active Australia questionnaire [17]. Diet was measured using the self-administered Anti-Cancer Council of Victoria food frequency questionnaire [18], and an overall index of diet quality was created using a scale of 1-100 (with 100 indicating high diet quality) [19]. Another behavioural variable was assessed, sedentary behaviour. This is defined as behaviours that involve sitting or lying down and is characterised by low metabolic equivalent intensity levels. It is important to measure both physical activity and sedentary behaviour because they have different patterns of risk factors [10]. It was measured using self-reported television viewing, as used previously [10]; this determined the total time spent watching television or videos in the preceding week. As a result of the large number of zero values reported for this variable, a constant of 0.5 was added to all values [20].

Statistical analysis The comparisons of baseline characteristics between glucose tolerance categories, NGT (normal glucose tolerance), IFG, IGT, and type 2 diabetes, were performed using analyses of covariance, controlling for age and sex (to accommodate graded age and sex differences between the categories).

In keeping with the model of Baron and Kenny [21], we first determined the direct association between SES and incident impaired glucose metabolism (step 1) (using multinomial regression analyses, with those with normoglycaemia as the reference group). To test the relative impact of each of the SES variables on glucose metabolism categories, education, income and occupation were assessed separately in a basic model, adjusting for age and sex. We then examined the association of SES with the baseline mediating factors, smoking, physical activity, diet quality and sedentary behaviour (step 2) (using linear regression for continuous and logistic regression for categorical variables), and the associations between baseline mediating factors and incident impaired glucose metabolism (step 3; multinomial regression analyses were performed). Next, we tested the extent to which mediating factors explain the relationship between SES and impaired glucose metabolism (step 4; again, using multinomial regression). Finally, the following components of the metabolic syndrome were integrated into the model, adiposity (waist circumference was included as the measure of adiposity because it is a better predictor of diabetes than BMI [22]), systolic blood pressure (as a continuous variable, categorised by every $10 \mathrm{mmHg}$ ), HDL-cholesterol (as a continuous variable), and high triacylglycerol levels (as a binary variable). At each stage, age and sex were included as covariates. Previous research highlights sex differences in the relationships between SES, adiposity and diabetes [11], therefore, sex by SES interactions were included in the models. In addition, to identify whether the value of education varied by age, age by education interactions were added to the regression models. The formula used to calculate the percentage of the variance explained by the mediating variables in the model was: (ORbasic model - ORadjusted)/ORbasic model -1$) \times 100$ [23]. Statistical analyses were conducted using SPSS 14.0.

\section{Results}

Baseline characteristics Table 1 presents the unadjusted baseline characteristics of the sample (only those with complete data, $n=4,405$ ), divided according to the categories of incident glucose metabolism. There were age and sex differences between the glucose tolerance categories, with a higher proportion of older people among those developing impaired glucose metabolism, and the IFG and type 2 diabetes groups were more likely to be male $(p<0.001)$. With adjustments made for age and sex, people with diabetes at follow-up reported higher smoking rates, lower physical activity, poorer diet quality, and elevated sedentary behaviour $(p<0.001)$, compared with those with normoglycaemia.

The group with NGT at follow-up had attained a significantly higher level of education than those with IGT and type 2 diabetes $(p<0.001)$, and reported higher total household incomes than those with incident diabetes $(p=0.036)$. There was a trend towards higher occupational grade in the NGT compared with IGT and type 2 diabetes groups but this was not statistically significant $(p=0.057)$.

Socioeconomic status, impaired glucose metabolism and mediating factors The association between the SES 
Table 1 Baseline characteristics of sample according to glucose tolerance categories at follow-up

\begin{tabular}{|c|c|c|c|c|}
\hline \multirow[t]{2}{*}{ Characteristics } & \multicolumn{4}{|c|}{ Glucose metabolism categories at follow-up } \\
\hline & NGT $(n=3,831)$ & IFG $(n=135)$ & IGT $(n=244)$ & Type 2 diabetes $(n=195)$ \\
\hline Age (years) & $49.2 \pm 12.2$ & $51.3 \pm 10.6^{\mathrm{a}}$ & $55.3 \pm 13.3^{\mathrm{a}}$ & $55.8 \pm 12.4^{\mathrm{a}}$ \\
\hline Male sex $(\%)$ & 43 & $59^{\mathrm{a}}$ & 44 & $52^{\mathrm{a}}$ \\
\hline Waist circumference $(\mathrm{cm})$ & $87.5 \pm 12.7$ & $97.2 \pm 11.9^{\mathrm{a}}$ & $94.0 \pm 12.9^{\mathrm{a}}$ & $98.4 \pm 14.4^{\mathrm{a}}$ \\
\hline Body mass index $\left(\mathrm{kg} / \mathrm{m}^{2}\right)$ & $26.0 \pm 4.3$ & $28.6 \pm 4.5^{\mathrm{a}}$ & $28.0 \pm 5.1^{\mathrm{a}}$ & $29.5 \pm 5.6^{\mathrm{a}}$ \\
\hline Systolic BP (mmHg) & $125 \pm 16$ & $131 \pm 17^{\mathrm{a}}$ & $134 \pm 19^{\mathrm{a}}$ & $136 \pm 17^{\mathrm{a}}$ \\
\hline Diastolic BP (mmHg) & $69 \pm 11$ & $73 \pm 11^{\mathrm{a}}$ & $71 \pm 12^{\mathrm{a}}$ & $75 \pm 12^{\mathrm{a}}$ \\
\hline Hypertension (\%) & $22^{\mathrm{a}}$ & $31^{\mathrm{a}}$ & $43^{\mathrm{a}}$ & $54^{\mathrm{a}}$ \\
\hline Total cholesterol $(\mathrm{mmol} / \mathrm{l})$ & $5.6 \pm 1.0^{\mathrm{a}}$ & $5.7 \pm 0.9$ & $5.9 \pm 1.1^{\mathrm{a}}$ & $5.9 \pm 1.0^{\mathrm{a}}$ \\
\hline HDL-cholesterol (mmol/l) & $1.5 \pm 0.4$ & $1.3 \pm 0.3^{\mathrm{a}}$ & $1.4 \pm 0.4^{\mathrm{a}}$ & $1.3 \pm 0.4^{\mathrm{a}}$ \\
\hline High triacylglycerols $(\%)$ & 15.3 & $26.7^{\mathrm{a}}$ & $31.0^{\mathrm{a}}$ & $42.6^{\mathrm{a}}$ \\
\hline Treated hypercholesterolaemia (\%) & 5 & 7 & 8 & $16^{\mathrm{a}}$ \\
\hline Fasting plasma glucose (mmol/l) & $5.2 \pm 0.4$ & $5.6 \pm 0.3^{\mathrm{a}}$ & $5.4 \pm 0.4^{\mathrm{a}}$ & $5.9 \pm 0.6^{\mathrm{a}}$ \\
\hline Post-load plasma glucose $(\mathrm{mmol} / \mathrm{l})$ & $5.4 \pm 1.1$ & $5.8 \pm 1.2^{\mathrm{a}}$ & $6.2 \pm 1.0^{\mathrm{a}}$ & $7.9 \pm 1.8^{\mathrm{a}}$ \\
\hline \multicolumn{5}{|l|}{ Smoking (\%) } \\
\hline Never smoked & 61 & 59 & 58 & $52^{\mathrm{a}}$ \\
\hline Ex-smoker & 28 & 33 & 31 & 31 \\
\hline Current smoker & 12 & 9 & 11 & 17 \\
\hline \multicolumn{5}{|l|}{ Exercise $(\%)$} \\
\hline No activity & 15 & $19^{\mathrm{a}}$ & 15 & $22^{\mathrm{a}}$ \\
\hline Insufficient & 30 & 33 & 32 & 38 \\
\hline Active & 55 & 48 & 53 & 41 \\
\hline Diet quality index $(0-100)$ & $66.7 \pm 12.4$ & $66.1 \pm 11.4$ & $66.3 \pm 13.4$ & $65.7 \pm 13.0$ \\
\hline Sedentary behaviour (h/week television viewing) ${ }^{\mathrm{b}}$ & $10(5-16)$ & $10(5-16)$ & $13(7-21)^{\mathrm{a}}$ & $12(7-19)$ \\
\hline \multicolumn{5}{|l|}{ Education $(\%)$} \\
\hline Secondary school education & 35 & 33 & $45^{\mathrm{a}}$ & $48^{\mathrm{a}}$ \\
\hline Trade/technician certificate & 29 & 33 & 31 & 29 \\
\hline Diploma/nursing/teaching & 15 & 15 & 9 & 10 \\
\hline Bachelor degree/postgraduate & 22 & 20 & 14 & 12 \\
\hline \multicolumn{5}{|l|}{ Weekly household income, \$ (\%) } \\
\hline$<400$ & 18 & 16 & $29^{\mathrm{a}}$ & $29^{\mathrm{a}}$ \\
\hline $400-800$ & 29 & 24 & 29 & 30 \\
\hline $800-1,500$ & 32 & 36 & 23 & 25 \\
\hline$>1,500$ & 21 & 23 & 19 & 16 \\
\hline \multicolumn{5}{|l|}{ Occupational grade $(\%)$} \\
\hline Professional & 50 & 58 & $45^{\mathrm{a}}$ & $45^{\mathrm{a}}$ \\
\hline White collar & 28 & 24 & 28 & 26 \\
\hline Blue collar & 22 & 19 & 27 & 29 \\
\hline
\end{tabular}

Data are presented as means \pm SD and percentages (\%)

${ }^{a}$ Planned comparisons between normal glucose tolerance (reference group) and other glucose tolerance categories $(p<0.05)$, after adjustment for age and sex

${ }^{\mathrm{b}}$ Sedentary behaviour (television viewing) values presented as medians and interquartile ranges

markers and impaired glucose metabolism (step 1) was tested, including each SES indicator in the age- and sexadjusted basic model. Of the SES indicators, education emerged as a predictor for incident IGT and type 2 diabetes $(p=0.002)$; however, income and occupational grade did not ( $p=0.103$ and $p=0.202$, respectively). Therefore, only education was included as the SES marker in the mediation steps and subsequent risk factor models.

Education was associated with all of the mediating health behaviours (step 2), after adjustment for age and sex. 
Table 2 Mediation step 3 showing relationships between health behaviour mediators and incident diabetes outcome

\begin{tabular}{ll}
\hline Health behaviour & Incident type 2 diabetes OR $(95 \% \mathrm{CI})$ \\
\hline Smoking & $1.74(1.17-2.60)^{*}$ \\
Exercise & $0.52(0.39-0.70)^{* * *}$ \\
Diet quality & $0.99(0.98-1.00)^{*}$ \\
Sedentary behaviour & $1.01(0.99-1.03)^{\mathrm{a}}$
\end{tabular}

Data presented are adjusted for age and sex. Smoking was categorised into two groups: current smokers and ex-/non-smokers

${ }^{\text {a }}$ Sedentary behaviour was significantly associated with IGT (not type 2 diabetes), OR 1.03 (95\% CI 1.01-1.04)

${ }^{*} p<0.05, * * * p<0.001$

Higher levels of education were associated with lower rates of smoking $(p<0.001)$ and increased physical activity ( $p<$ $0.001)$, and associated with improved diet quality $(p<$ $0.001)$ and reduced sedentary behaviour $(p<0.001)$.

Table 2 presents the mediating variables related to type 2 diabetes (step 3). People who developed type 2 diabetes were more likely to smoke $(p=0.007)$, be physically inactive $(p<0.001)$, and have poor diet quality $(p=0.049)$. Sedentary behaviour was not related to type 2 diabetes $(p=$ 0.23 ) but it was significantly associated with incident IGT $(p=0.001)$.

The final stage of the mediation pathway (step 4) is displayed in Table 3, demonstrating the effect of health behaviours on the relationship between SES and impaired glucose metabolism. The first model shown reiterates step
1: the relationship between education and the glucose tolerance categories. Education was shown to predict IGT and type 2 diabetes; those people in the lowest education categories were at significantly greater risk of developing IGT and type 2 diabetes than the group with the highest level of education, independent of age and sex. The second model included the potential mediating health behaviour variables; current smokers were significantly more likely to develop type 2 diabetes compared with non-smokers ( $p=$ $0.019)$, and exercise was a significant predictor of IFG $(p=0.043)$ and type 2 diabetes $(p=0.002)$, but not IGT $(p=$ $0.96)$. Diet quality did not emerge as a significant predictor of abnormal glucose metabolism $(p=0.73)$, whereas higher levels of sedentary behaviour were predictive of increased risk of IGT ( $p=0.001)$. The impact of education on IGT and type 2 diabetes was attenuated by the addition of smoking, exercise and sedentary behaviour, although the lowest education group remained significantly more likely to develop type 2 diabetes compared with those with a degree education. Cumulatively, health behaviours explained $27 \%$ of the relationship between baseline socioeconomic factors and incident type 2 diabetes, and $28 \%$ of the relationship between socioeconomic variables and IGT. The full model, with the inclusion of the components of the metabolic syndrome, showed that adiposity was significantly related to the development of IFG, IGT and type 2 diabetes $(p<0.001)$. Systolic blood pressure and high levels of triacylglycerols were predictive of IGT ( $p=0.006$ and $p=0.001$, respectively) and type 2 diabetes ( $p=0.002$ and $p<0.001$, respectively),
Table 3 OR $(95 \% \mathrm{CI})$ of having incident impaired fasting glucose, impaired glucose tolerance, or type 2 diabetes according to education categories, with normal glucose tolerance as the reference group

Normal glucose tolerance was the reference group. Only includes people with complete data $(n=4,406)$. Health behaviours included in models: smoking, exercise, diet and sedentary behaviour. Components of the metabolic syndrome included in the model: adiposity, blood pressure, HDL-cholesterol and high triacylglycerol levels ${ }^{*} p<0.05 ; * * p<0.01$

\begin{tabular}{|c|c|c|c|c|c|c|}
\hline \multirow[t]{2}{*}{ Adjusted models } & \multicolumn{2}{|l|}{ IFG } & \multicolumn{2}{|l|}{ IGTe } & \multicolumn{2}{|c|}{ Type 2 diabetes } \\
\hline & OR & $95 \% \mathrm{CI}$ & OR & $95 \% \mathrm{CI}$ & OR & $95 \% \mathrm{CI}$ \\
\hline \multicolumn{7}{|l|}{ First model—adjusted for age and sex } \\
\hline \multicolumn{7}{|l|}{ Education } \\
\hline Bachelor degree/postgraduate & 1 & & 1 & & 1 & \\
\hline Diploma/nursing/teaching & 1.16 & $0.64-2.11$ & 0.86 & $0.50-1.45$ & 1.15 & $0.62-2.12$ \\
\hline Trade/technician certificate & 1.10 & $0.67-1.81$ & 1.42 & $0.94-2.15$ & 1.46 & $0.89-2.38$ \\
\hline Secondary school education & 1.05 & $0.63-1.73$ & 1.60 & $1.07-2.40^{*}$ & 2.10 & $1.31-3.37 * *$ \\
\hline \multicolumn{7}{|c|}{ Second model—adjusted for age, sex, and health behaviours } \\
\hline \multicolumn{7}{|l|}{ Education } \\
\hline Bachelor degree/postgraduate & 1 & & 1 & & 1 & \\
\hline Diploma/nursing/teaching & 1.18 & $0.65-2.14$ & 0.83 & $0.48-1.42$ & 1.07 & $0.58-1.99$ \\
\hline Trade/technician certificate & 1.10 & $0.67-1.83$ & 1.30 & $0.85-1.98$ & 1.30 & $0.79-2.14$ \\
\hline Secondary school education & 1.06 & $0.63-1.77$ & 1.43 & $0.94-2.16$ & 1.80 & $1.11-2.92 *$ \\
\hline \multirow{2}{*}{\multicolumn{7}{|c|}{$\begin{array}{l}\text { Third model—adjusted for age, sex, health behaviours, and components of the metabolic syndrome } \\
\text { Education }\end{array}$}} \\
\hline & & & & & & \\
\hline Bachelor degree/postgraduate & 1 & & 1 & & 1 & \\
\hline Diploma/nursing/teaching & 1.07 & $0.58-1.96$ & 0.74 & $0.43-1.29$ & 0.95 & $0.51-1.79$ \\
\hline Trade/technician certificate & 1.05 & $0.63-1.75$ & 1.23 & $0.80-1.88$ & 1.24 & $0.75-2.06$ \\
\hline Secondary school education & 0.99 & $0.59-1.66$ & 1.32 & $0.87-2.00$ & 1.70 & $1.04-2.79 *$ \\
\hline
\end{tabular}


although HDL-cholesterol was not $(p=0.40$ and $p=0.48$, respectively). The addition of these biological markers of diabetes explained a further $9 \%$ of the SES-type 2 diabetes relationship and $19 \%$ of the SES-IGT association. The group with low levels of education still showed significantly greater risk of developing type 2 diabetes than the group with the highest education, even after accounting for behavioural and biological risk factors. Sex by SES and age by education interactions were included in each model but neither interaction was significant and these terms were removed.

\section{Discussion}

These analyses showed that socioeconomic status predicted diabetes risk across a range of glucose metabolism categories, and that this relationship was partly mediated by two health behaviours - smoking and physical activity.

This study had a number of key strengths in relation to previous research exploring the socioeconomic gradient in type 2 diabetes. This is the first study to use a national, populationbased sample, with data across all categories of glucose metabolism. Similar studies have only included participants from restricted occupational settings [11] or community samples [12]. In addition, these novel analyses of the risk factors for diabetes aetiology explicitly examined the behavioural pathways through which socioeconomic risk factors may influence the impairment of glucose metabolism. It is also the first study to use a statistically appropriate, theorydriven method to explore this mediation. Previous work has suggested that the relationship between SES and diabetes incidence may be partially explained by behaviours [11] and obesity [13]; however, the necessary steps to establish mediation had not been completed and therefore mediation could not be affirmed. The present study used the mediation model devised by Baron and Kenny [21] to examine the role of health behaviours in the SES-diabetes relationship.

The first mediation step established an inverse relationship between SES and diabetes incidence. This supports previous research, that being in a low socioeconomic group increases the risk of developing type 2 diabetes $[4,5,11,13]$. Data from two studies from the USA found SES to be an important risk factor for diabetes in women $[5,13]$; however, both studies included doctor-diagnosed diabetes as their outcome. This is a less precise assessment of diabetes than the OGTT because approximately half of all diabetes is undiagnosed [24].

The next steps of the mediation process identified the relationship between socioeconomic factors and the potential mediators, the health behaviours, (smoking, physical activity, diet and sedentary behaviour), and demonstrated the predictive impact of the behaviours on impaired glucose metabolism. Our statistical associations supported empirical evidence that socioeconomic factors do influence the health behaviours examined [9], and that health behaviours predict the development of diabetes [2, 25, 26].

Finally, we tested the mediation step demonstrating the effect of the health behaviours on the socioeconomic gradient in diabetes incidence. Smoking and physical activity attenuated the impact of SES on IGT and type 2 diabetes, adhering to the requirements of a mediator at each step of mediation. Diet and sedentary behaviour, however, did not retain significance with education in the model so cannot be considered possible mediators of the SESdiabetes relationship.

Understanding the chronological sequence in which risk factors exert their impact on the disease process helps to explain why, despite the inclusion of adiposity and the other biological risk factors in the final model, only an additional $9 \%$ was explained. One's involvement in healthy behaviours influences the development of obesity and lipid and glucose profiles [10], and by including health behaviours earlier in our statistical models, much of the variance that could have been explained by the biological risk factors had already been attributed to health behaviours.

Despite the inclusion of the mediators, education remained significant even in the fully adjusted models. Other pathways must therefore exist to explain a proportion of this relationship. Previous research indicates that psychosocial risk factors, such as depression and work stress, may provide other mechanisms through which SES influences diabetes risk $[11,27]$.

By including multiple outcomes of impaired glucose metabolism (IFG and IGT, as well as type 2 diabetes), this study aimed to identify the stage of the disease progression at which risk factors influence diabetes risk. We showed an effect of SES on the development of IGT and diabetes but found that socioeconomic factors did not significantly predict IFG. This is an unexpected finding because it was hypothesised that socioeconomic factors would be relevant from an early point in the disease process. The IFG group shared more similarities with the NGT group in terms of their socioeconomic profiles than with IGT or type 2 diabetes. Previous work has shown that those people with IGT are more likely to go on to develop type 2 diabetes than people with IFG [2]. Therefore, fewer people with IFG will develop type 2 diabetes, and the socioeconomic gradient may be less pronounced because of the heterogeneity in this IFG population. An earlier study also failed to show a relationship between socioeconomic factors and IFG; however, in that cross-sectional study, IGT, too, was shown not to relate to SES [4]. Very few studies have investigated risk factors for the early phases of diabetes progression and therefore more work is required to clarify this finding.

We have also shown that education was a more sensitive marker of socioeconomic status for the development of 
diabetes, compared with income and occupational grade. It is interesting that neither income nor occupation emerged as significant predictors of impaired glucose metabolism in this sample. Different markers of SES measure varying elements of one's socioeconomic position. Educational attainment is often considered to be a more stable marker of SES, being less susceptible to reverse-causality effects than other markers because it incorporates an element of childhood social environment [28], as well as predicting adult socioeconomic circumstances. Household income is an indicator of the material conditions of one's environment [28]; however, this measure of SES is complicated in retired populations, whose income is not commensurate with other socioeconomic aspects of their lives. Another alternative is occupational grade, easily collected and a measure of societal position according to occupational status and power [29]; however, this marker can exclude unemployed populations. Our finding that education is more closely related to glucose metabolism and therefore a more sensitive measure of socioeconomic position in these analyses corroborates previous work [30], although other studies have shown occupation and income to relate to diabetes risk $[5,11]$. One's education may be more likely to affect one's understanding and knowledge of the health benefits of preventative behaviours [25] than having a high income or being in a high status occupation. This could explain why education shows a closer association with diabetes than other SES indicators. Another possibility is that, as an earlier life indicator of SES, education has a greater effect on the formation of behaviour habits that go on to shape behaviours in later life and subsequently influence health.

The national, population-based nature of this sample suggests that these findings could be generalised across populations of similar ethnicity and socioeconomic range, and the quality of the glucose tolerance data gives this work considerable weight. There are, however, limitations to be considered. The self-report recording of the behaviours means that the contributions of these variables may not be entirely accurate. Objective measures of behaviours, such as using accelerometers to record physical activity, could facilitate more reliable and valid measurements in the future. Although diet was not shown to be a mediator in these analyses, diet is very difficult to measure accurately [31]. Although we used diet quality to derive a multidimensional measure of diet, it is possible that individual components of diet, such as quality of fat or carbohydrate intake, might be more relevant to diabetes risk [26]. The origins of socioeconomic and behavioural risk factors can go back to the very early years of life, even in utero [8]. Unfortunately, the earliest indicator of socioeconomic position available for these analyses was education, and therefore we were not able to examine the socioenvironmental factors that influence early development and promote disease later in life. The small numbers of cases in different education categories meant that sex-specific analyses could not be performed. Despite significant support for the use of mediation models to enable a move beyond the simple observation of a relationship between an exposure and outcome [32], some literature indicates that unmeasured confounding between the mediator and the outcome may bias the effect of the exposure on the outcome [33]. It is possible that, as with all mediated estimates, the mediated effect estimates presented in this paper may be subject to confounding bias.

This study provides further evidence of the link between socioeconomic inequality and diabetes risk, and implicates behaviours as pathways through which social adversity manifests itself in glucose metabolism impairment. By understanding the risk factors that explain a proportion of the SES-diabetes relationship, we can then identify interventions to target modifiable behaviours. Efforts should focus on providing additional supports at the social and environmental level to disadvantaged groups to promote healthy behaviours and to begin to eliminate socioeconomic inequalities in diabetes risk.

Acknowledgements Thanks to Professor A. Forbes, from Monash University, for his contribution towards the statistical discussion. E.D. Williams was funded by travelling fellowships from the European Association for the Study of Diabetes and the British Council to complete this work. J.E. Shaw is supported by an NHMRC Fellowship (586623). The AusDiab study co-coordinated by the Baker IDI Heart and Diabetes Institute, gratefully acknowledges the generous support given by: National Health and Medical Research Council (NHMRC grant 233200); Australian Government Department of Health and Ageing; Abbott Australasia Pty; Alphapharm Pty; AstraZeneca; Bristol-Myers Squibb; City Health Centre-Diabetes Service-Canberra; Department of Health and Community Services, NT; Department of Health and Human Services, TAS; Department of Health, NSW; Department of Health, WA; Department of Health, SA; Department of Human Services, VIC; Diabetes Australia; Diabetes Australia NT; Eli Lilly Australia; estate of the late E. Wilson; GlaxoSmithKline; Jack Brockhoff Foundation; Janssen-Cilag; Kidney Health Australia; Marian \& FH Flack Trust; Menzies Research Institute; Merck Sharp \& Dohme; Novartis Pharmaceuticals; Novo Nordisk Pharmaceuticals; Pfizer Pty; Pratt Foundation; Queensland Health; Roche Diagnostics Australia; Royal Prince Alfred Hospital, Sydney; sanofi-aventis; and sanofi-synthelabo. Also, for their invaluable contribution to the set-up and field activities of AusDiab, we are enormously grateful to A. Allman, B. Atkins, S. Bennett, A. Bonney, S. Chadban, M. de Courten, M. Dalton, D. Dunstan, T. Dwyer, H. Jahangir, D. Jolley, D. McCarty, A. Meehan, N. Meinig, S. Murray, K. O'Dea, K. Polkinghorne, P. Phillips, C. Reid, A. Stewart, R. Tapp, H. Taylor, T. Whalen and F. Wilson.

Duality of interest The authors declare that there is no duality of interest associated with this manuscript.

\section{References}

1. Shaw JE, Sicree RA, Zimmet PZ (2010) Global estimates of the prevalence of diabetes for 2010 and 2030. Diabetes Res Clin Pract $87: 4-14$ 
2. Magliano DJ, Barr EL, Zimmet PZ et al (2007) Glucose indices, health behaviours and incidence of diabetes in Australia: the AusDiab Study. Diab Care 31:267-272

3. Marmot MG, Kogevinas M, Elston MA (1987) Social/economic status and disease. Annu Rev Public Health 8:111-137

4. Rathmann W, Haastert B, Giani G et al (2006) Is inflammation a causal chain between low socioeconomic status and type 2 diabetes? Results from the KORA Survey 2000. Eur J Epidemiol 21:55-60

5. Robbins JM, Vaccarino V, Zhang H, Kasl SV (2005) Socioeconomic status and diagnosed diabetes incidence. Diabetes Res Clin Pract 68:230-236

6. Maty SC, James SA, Kaplan GA (2010) Life-course socioeconomic position and incidence of diabetes mellitus among blacks and whites: the Alameda County Study, 1965-1999. Am J Public Health 100:137-145

7. Espelt A, Borrell C, Roskam AJ et al (2008) Socioeconomic inequalities in diabetes mellitus across Europe at the beginning of the 21st century. Diabetologia 51:1971-1979

8. Gluckman PD, Hanson MA, Cooper C, Thornburg K (2008) Effect of in utero and early-life conditions on adult health and disease. N Engl J Med 359:61-73

9. Wardle J, Steptoe A (2003) Socioeconomic differences in attitudes and beliefs about healthy lifestyles. J Epidemiol Community Health 57:440-443

10. Dunstan DW, Salmon J, Owen N et al (2005) Associations of TV viewing and physical activity with the metabolic syndrome in Australian adults. Diabetologia 48:2254-2261

11. Kumari M, Head J, Marmot M (2004) Prospective study of social and other risk factors for incidence of type 2 diabetes in the Whitehall II Study. Arch Intern Med 164:1873-1880

12. Agardh EE, Ahlbom A, Andersson T et al (2004) Explanations of socioeconomic differences in excess risk of type 2 diabetes in Swedish men and women. Diab Care 27:716-721

13. Krishnan S, Cozier YC, Rosenberg L, Palmer JR (2010) Socioeconomic status and incidence of type 2 diabetes: results from the Black Women's Health Study. Am J Epidemiol 171:564-570

14. Briganti EM, Shaw JE, Chadban SJ et al (2003) Untreated hypertension among Australian adults: the 1999-2000 Australian Diabetes, Obesity and Lifestyle Study (AusDiab). Med J Aust 179:135-139

15. Dunstan DW, Zimmet PZ, Welborn TA et al (2002) The Australian Diabetes, Obesity and Lifestyle Study (AusDiab) methods and response rates. Diabetes Res Clin Pract 57:119-129

16. Australian Institute of Health and Welfare (1998) Standard questions on the use of tobacco among adults. Australian Institute of Health and Welfare, Canberra

17. Australian Institute of Health and Welfare (2003) The Active Australia Survey: a guide and manual for implementation, analysis and reporting. Australian Institute of Health and Welfare, Canberra

18. Ireland P, Jolley D, Giles GG et al (1994) Development of the Melbourne FFQ: a food frequency questionnaire for use in an
Australian prospective study involving an ethnically diverse cohort. Asia Pac J Clin Nutr 3:19-31

19. McNaughton SA, Dunstan DW, Ball K, Shaw J, Crawford D (2009) Dietary quality is associated with diabetes and cardiometabolic risk factors. J Nutr 139:734-742

20. McDonald JH (2009) Handbook of biological statistics, 2nd edn. Sparky House, Baltimore, pp 160-164

21. Baron RM, Kenny DA (1986) The moderator-mediator variable distinction in social psychological research: conceptual, strategic, and statistical considerations. J Pers Soc Psychol 51:1173-1182

22. Klein S, Allison DB, Heymsfield SB et al (2007) Waist circumference and cardiometabolic risk: a consensus statement from Shaping America's Health: Association for Weight Management and Obesity Prevention; NAASO, The Obesity Society; the American Society for Nutrition; and the American Diabetes Association. Obesity 15:1061-1067

23. Mora S, Cook N, Buring JE, Ridker PM, Lee IM (2007) Physical activity and reduced risk of cardiovascular events: potential mediating mechanisms. Circulation 116:2110-2118

24. Dunstan DW, Zimmet PZ, Welborn TA et al (2002) The rising prevalence of diabetes and impaired glucose tolerance. Diab Care $25: 829-834$

25. Chiolero A, Faeh D, Paccaud F, Cornuz J (2008) Consequences of smoking for body weight, body fat distribution, and insulin resistance. Am J Clin Nutr 87:801-809

26. Hu FB, van Dam RM, Liu S (2001) Diet and risk of type II diabetes: the role of types of fat and carbohydrate. Diabetologia 44:805-817

27. Chida Y, Hamer M (2008) An association of adverse psychosocial factors with diabetes mellitus: a meta-analytic review of longitudinal cohort studies. Diabetologia 51:2168-2178

28. Geyer S, Hemstrom O, Peter R, Vagero D (2006) Education, income, and occupational class cannot be used interchangeably in social epidemiology. Empirical evidence against a common practice. J Epidemiol Community Health 60:804-810

29. Winkleby MA, Jatulis DE, Frank E, Fortmann SP (1992) Socioeconomic status and health: how education, income, and occupation contribute to risk factors for cardiovascular disease. Am J Public Health 82:816-820

30. Maty SC, Everson-Rose SA, Haan MN, Raghunathan TE, Kaplan GA (2005) Education, income, occupation, and the 34-year incidence (1965-99) of type 2 diabetes in the Alameda County Study. Int J Epidemiol 34:1274-1281

31. Kristal AR, Peters U, Potter JD (2005) Is it time to abandon the food frequency questionnaire? Cancer Epidemiol Biomark Prev $14: 2826-2828$

32. Hafeman DM, Schwartz S (2009) Opening the black box: a motivation for the assessment of mediation. Int $\mathrm{J}$ Epidemiol 38:838-845

33. Kaufman JS, MacLehose RF, Kaufman S (2004) A further critique of the analytic strategy of adjusting for covariates to identify biologic mediation. Epidemiol Perspect Innov 1:4 